\title{
Mobile Phones used by Healthcare Workers: The Potential Role in Transmission of Healthcare Associated Infections
}

\author{
Amira M. Sultan ${ }^{\text {** }}$ and Mohammad A. Ahmed ${ }^{2}$ \\ ${ }^{1}$ Department of Medical Microbiology and Immunology, Faculty of Medicine, Mansoura \\ University, Al Gomhoria St., Mansoura, Egypt \\ ${ }^{2}$ Department of Anaesthesia, Faculty of Medicine-Mansoura University, Mansoura, Egypt \\ *Corresponding author
}

\section{Keywords}

Mobile phones, Healthcare workers, Healthcare associated infections, Bacterial contamination, Staphylococcus epidermidis

Article Info

Accepted:

07 April 2019

Available Online:

10 May 2019

\section{A B S T R A C T}

To identify bacterial contamination of cellular phones used by healthcare workers (HCWs) and to investigate antibiotic resistance patterns of recovered isolates. In addition, we assessed the possible risk factors for contamination of mobile phones. Mobile phones were sampled from HCWs across inpatient, outpatient and intensive care wards in Mansoura Emergency Hospital. Isolated bacteria were identified and subjected to disk diffusion test to detect their antibiotic resistance patterns. Sampled mobile phones had a contamination rate of $90.4 \%(\mathrm{P}=0.00)$. Staphylococcus epidermidis was the commonest isolated organism (41.3\%). Significant risk factors included the usage of mobile cover and lack of history of mobile phones disinfection by the HCWs. Bacterial isolates demonstrated the least antimicrobial resistance toward imipenem (11.9\%) and amikacin (17.3\%). Out of the isolated Staphylococcus aureus, $27.9 \%$ were methicillin resistant while $32.7 \%$ of the isolated Gram-negative bacteria were producers of extended spectrum $\beta$-lactamases. Besides, multidrug resistant isolates constituted $41.1 \%$ of the tested bacteria. We demonstrated that mobile phones may serve as a vehicle for transmission of healthcare associated infections. Therefore, education of HCWs and limitation of mobile phones usage in high-risk settings parallel to frequent disinfection of hands and mobile phones should be implemented.

\section{Introduction}

Healthcare associated infections (HAIs) represent a serious problem in different healthcare settings as they increase mortality, morbidity, hospital stay and medical cost. These infections are transmitted through hands of healthcare workers (HCWs), contaminated patient care items and other inanimate hospital objects (Schultz et al.,
2003; Singh et al., 2010). Personal electronic devices as personal digital assistants and hand-held computers were found to play a significant role in transmission of HAIs (Bellamy et al., 1998; Isaacs et al., 1998).

Throughout the last decade, mobile phones have emerged as portable communication devices that became essential in modern life. Affordable and user-friendly operating 
systems have made mobile phones accessible to a wide range of users all over the world. Many HCWs in different settings and locations currently use mobile phones for communication. Mobile phones frequently come in contact with the body surfaces of their users as face and hands. Furthermore, they commonly touch environmental surfaces present in healthcare settings. Therefore, mobile phones are potentially liable for contamination with various microorganisms (Pal et al., 2015). Direct handling of mobile phones without proper disinfection can make them reservoir and vehicles of microorganisms associated with HAIs (França et al., 2018). Implementation of proper disinfection of mobile phones was reported to be effective in limiting the spread of these pathogens (Arora et al., 2009; Trivedi et al., 2011).

Despite all the benefits provided by mobile phones, they might pose a health problem by harboring different microorganisms and thus contributing in the transmission of HAIs. Doctors and other HCWs working in highrisk areas as intensive care units (ICUs) are more exposed to pathogenic microorganisms. Thus, mobile phones used by those HCWs may act as a vehicle spreading pathogens to other locations (Kakote et al., 2012). In addition, mobile phones used by HCWs can transmit resistant bacteria that are commonly present in healthcare settings environment to household and other community settings (Bhat et al., 2011; Pal et al., 2015).

Previous studies demonstrated that organisms recovered from mobile phones in the healthcare settings included Staphylococcus epidermidis (S. epidermidis), Staphylococcus aureus (S. aureus), Pseudomonas aeruginosa ( $P$. aeruginosa), Klebsiella pneumoniae (K. pneumoniae) and Escherichia coli (E. coli) (Ulger et al., 2009; Trivedi et al., 2011). Multidrug resistant (MDR) bacteria were also recovered from mobile phones (Ulger et al., 2009; Tekerekoglu et al., 2011).

Although mobile phones are routinely used, they are usually not adequately cleaned by HCWs. Moreover, improper implementation of hand hygiene by HCWs could increase the risk of mobile phones contamination. Guidelines for limitation of mobile phone usage, particularly in high-risk areas, and regular disinfection of phones are lacking in many healthcare settings. Besides, many health professionals are even unaware of the risk carried by these phones (Pal et al., 2015).

Studies that evaluated the role of mobile phones in development of HAIs in our locality are scarce. Therefore, we carried out this study to identify bacterial contamination of cellular phones used by HCWs and to investigate antibiotic resistance patterns of recovered isolates. Besides, the possible risk factors for contamination of mobile phones were evaluated.

\section{Materials and Methods}

\section{Setting}

A hospital-based study was performed in Mansoura Emergency Hospital in collaboration with Medical Microbiology and Immunology Department, Mansoura Faculty of Medicine, Mansoura- Egypt. The study protocol was reviewed and approved by the Institutional Review Board. An informed consent was taken, after full explanation of the study, from all participating HCWs.

\section{Sample collection}

Mobile phones were sampled from randomly participating $\mathrm{HCWs}$ across inpatient wards, outpatient clinics and ICUs in Mansoura Emergency Hospital during the months of June and July, 2018. Participating HCWs 
included doctors, nurses and other HCWs as technicians and therapists. Data of participating $\mathrm{HCWs}$ were collected as profession, location and gender. In addition, other possible risk factors for mobile phones contamination were recorded such as the type of mobile phone (touch-screen or keypad), use of mobile cover, site of mobile placement and previous history of mobile phone disinfection by HCWs. All participants were excluded from further enrollment in the study to ensure that each phone was submitted for one time only. Samples were collected in aseptic way by sterile cotton swabs. In order to sample each mobile phone, a sterile swab was moistened with sterile saline and rolled over all surfaces of the phone including screen, sides and mobile cover if present.

\section{Culture and identification}

All collected swabs were immediately cultured onto blood agar plates. Cultured plates were aerobically incubated for 24 hours at $37^{\circ} \mathrm{C}$. Following Gram-staining of isolated organisms, Gram-negative bacteria were subcultured on MacConkey agar plates for further identification. Identification of isolated bacteria was performed according to standard protocols by colonial morphology, Gram-staining, different biochemical reactions and analytical profile indices (API) strips.

\section{Antimicrobial susceptibility testing}

All recovered isolates were subjected to disk diffusion test in order to identify their antibiotic sensitivity profiles. Disk diffusion test was conducted using Mueller-Hinton agar (MHA) plates and a panel of ten antibiotic disks (Oxoid, UK). The test procedure and interpretation of results were carried out along with the guidelines of clinical and laboratory standard institute (CLSI) (CLSI, 2018). E-test strips (bioMerieux, France) on MHA plates were used to determine vancomycin minimum inhibitory concentration as per manufacturer's guidelines. The CLSI breakpoints for resistance were used for results interpretation (CLSI, 2018). Bacterial isolates showing resistance to three or more antimicrobial classes were counted as MDR isolates (Vergnano et al., 2011; Seliem and Sultan, 2018).

\section{Detection of methicillin resistant staphylococcus aureus}

Identified S. aureus isolates were subjected to cefoxitin disk diffusion test in order to detect methicillin resistance. Following the CLSI guidelines, the cefoxitin disk diffusion test was conducted by standard procedure using MHA plates and $30 \mu$ g-cefoxitin disks (Oxoid, UK). After incubation of the inoculated plate at $35{ }^{\circ} \mathrm{C}$ for 24 hours, the inhibitory zone diameter was measured. Isolates with a diameter of $\leq 21 \mathrm{~mm}$ were reported as methicillin resistant $S$. aureus (MRSA) (CLSI, 2018).

\section{Detection of extended spectrum $\beta$ - lactamases production}

Gram-negative bacilli that demonstrated resistance to cefotaxime or ceftazidime were further tested for the production of extended spectrum $\beta$-lactamases (ESBL). Detection of ESBL production was conducted by disk diffusion clavulanate inhibition test using both ceftazidime and cefotaxime alone and in combination with clavulanate as per the guidelines of CLSI (CLSI, 2018).

A standard disk diffusion test was conducted by using MHA plates, single and combined antibiotic disks (Oxoid, UK). Briefly, one disk of ceftazidime $(30 \mu \mathrm{g})$ and a second disk of ceftazidime-clavulanate $(30 / 10 \quad \mu \mathrm{g})$ were placed onto the inoculated MHA at a distance of $2 \mathrm{~cm}$. Similarly, one disk of cefotaxime (30 
$\mu \mathrm{g})$ and another disk of cefotaximeclavulanate $(30 / 10 \mu \mathrm{g})$ were placed onto the same MHA plate. Following that, plates were incubated at $35^{\circ} \mathrm{C}$ for 18 hours. A confirmed ESBL producing strain was reported when there is $\geq 5-\mathrm{mm}$ increase in the inhibition zone diameter for either antimicrobial agent combined with clavulanate versus the inhibition zone diameter of the antimicrobial agent alone (CLSI, 2018).

\section{Statistical analysis}

The SPSS statistical package software for windows version 22 (SSPS Inc, Pennsylvania, USA) was used to carry out the statistical analysis of our data. Differences between two categorical variables were assessed by using the Chi square test. In order to identify statistically significant differences between three variables, the one-way analysis of variance (ANOVA) was performed. $\mathrm{P}$ value < 0.05 was considered indicative of significant difference.

\section{Results and Discussion}

The present study included the mobile phones belonging to a total number of $146 \mathrm{HCWs}$ from different locations in Mansoura Emergency Hospital; 55 HCWs (37.7\%) from inpatient wards, 51 (34.9\%) from outpatient clinics and $40(27.4 \%)$ from ICUs. Out of 146 study participants, 41 (28.1\%) were doctors, $90(61.6 \%)$ were nurses and $15(10.3 \%)$ were other HCWs as demonstrated in Table 1.

During our study, bacterial growth was detected from 132 mobile phones with a contamination rate of $90.4 \%$ while 14 mobile phones $(9.6 \%)$ revealed negative cultures which was statistically significant $(\mathrm{P}=0.00)$. Single type of bacteria was recovered from 71 (48.6\%) mobile phones while two types of bacterial growth were isolated from 46
(31.5\%) mobile phones. A number of 15 $(10.3 \%)$ mobile phones were contaminated with three types of bacteria as demonstrated in Figure 1.

Out of the sampled 146 mobile phones, 86 (58.9\%) grew S. epidermidis, 44 (30.1\%) methicillin sensitive $S$. aureus (MSSA), 21 (14.4\%) E. coli, 17 (11.6\%) MRSA, 17 $(11.6 \%) \quad K$. pneumoniae, $11 \quad(7.5 \%) \quad P$. aeruginosa, $6 \quad(4.1 \%)$ Acinetobacter baumannii (A. baumannii) and 6 (4.1\%) Bacillus anthracoid as demonstrated in Table 2.

A total number of 208 bacterial isolates were recovered from the contaminated mobile phones. Of the recovered 208 isolates, 116 $(55.8 \%)$ were established nosocomial pathogens. Isolated bacteria included 153 (73.6\%) Gram-positive and 55 (26.4\%) Gramnegative bacteria. The most commonly isolated organism was $S$. epidermidis as constituted $41.3 \%(86 / 208)$ of the total isolates. Out of the 61 recovered $S$. aureus isolates, $44(72.1 \%)$ were methicillin sensitive and $17(27.9 \%)$ were methicillin resistant.

Mobile phones belonged to doctors had the least contamination rate $(87.8 \%)$, while phones belonged to nurses and other HCWs had contamination rates of $91.1 \%$ and $93.3 \%$ respectively. There was no significant association between the profession of HCWs and contamination rate of mobile phones as demonstrated in Table 3.

The mobile phones screened in the outpatient clinics had the highest contamination rate $(98.0 \%)$ followed by inpatient wards $(89.1 \%)$ and ICUs $(82.5 \%)$. The rate of contamination of mobile phones was not significantly related to the type of clinical setting as shown in Table 4. 
Table.1 Distribution of mobile phones in relation to location and profession of healthcare workers

\begin{tabular}{|c|c|c|c|c|}
\hline \multirow{2}{*}{ Location } & \multicolumn{2}{|c|}{ Profession of healthcare workers } & \multirow{2}{*}{ Total } \\
\cline { 2 - 4 } & Doctors & Nurses & Other HCWs & \\
\hline Inpatient wards & $10(24.4)$ & $39(43.3)$ & $6(40.0)$ & $55(37.7)$ \\
\hline Outpatient clinics & $18(43.9)$ & $29(32.2)$ & $4(26.7)$ & $51(34.9)$ \\
\hline Intensive care units & $13(31.7)$ & $22(24.4)$ & $5(33.3)$ & $40(27.4)$ \\
\hline Total & $41(100)$ & $90(100)$ & $15(100)$ & $146(100)$ \\
\hline
\end{tabular}

HCWs: Healthcare workers

Values are expressed as No (\%)

Table.2 Types of bacterial isolates recovered from mobile phones

\begin{tabular}{|c|c|}
\hline Bacterial isolates & $\begin{array}{c}\text { Mobile phones } \\
\text { No= 146(\%) }\end{array}$ \\
\hline \multicolumn{2}{|c|}{ Gram-positive bacteria } \\
\hline Staphylococcus epidermidis & $86(58.9 \%)$ \\
\hline MSSA & $44(30.1 \%)$ \\
\hline MRSA & $17(11.6 \%)$ \\
\hline \multicolumn{2}{|c|}{ Gacillus anthracoid } \\
\hline \multicolumn{2}{|c|}{ Gram-negative bacteria } \\
\hline Escherichia coli & $21(14.4 \%)$ \\
\hline Klebsiella pneumoniae & $17(11.6 \%)$ \\
\hline Pseudomonas aeruginosa & $11(7.5 \%)$ \\
\hline Acinetobacter baumannii & $6(4.1 \%)$ \\
\hline
\end{tabular}

MSSA: Methicillin sensitive Staphylococcus aureus

MRSA: Methicillin resistant Staphylococcus aureus

Table.3 Relationship between the profession of healthcare workers and contamination rate of mobile phones

\begin{tabular}{|l|c|c|c|c|}
\hline Profession & Doctors & Nurses & Other HCWs & P value \\
\hline Rate of contamination $(\boldsymbol{\%})$ & $87.8 \%$ & $91.1 \%$ & $93.3 \%$ & 0.89 \\
& $(36 / 41)$ & $(82 / 90)$ & $(14 / 15)$ & \\
\hline
\end{tabular}

HCWs: Healthcare workers

Table.4 Relationship between the type of clinical setting and contamination rate of mobile phones

\begin{tabular}{|l|c|c|c|c|}
\hline Type of clinical setting & $\begin{array}{c}\text { Inpatient } \\
\text { wards }\end{array}$ & $\begin{array}{c}\text { Outpatient } \\
\text { clinics }\end{array}$ & $\begin{array}{c}\text { Intensive care } \\
\text { units }\end{array}$ & P value \\
\hline Rate of contamination (\%) & $89.1 \%$ & $98.0 \%$ & $82.5 \%$ & 0.69 \\
& $(49 / 55)$ & $(50 / 51)$ & $(33 / 40)$ & \\
\hline
\end{tabular}


Table.5 Risk factors associated with contamination of mobile phones

\begin{tabular}{|c|c|c|c|c|}
\hline Risk factor & $\begin{array}{c}\text { Total number } \\
\text { of mobile } \\
\text { phones }\end{array}$ & $\begin{array}{c}\text { Number of } \\
\text { contaminated } \\
\text { mobile phones }\end{array}$ & $\begin{array}{c}\text { Rate of } \\
\text { contamination } \\
(\%)\end{array}$ & P value \\
\hline \multicolumn{5}{|l|}{ Gender } \\
\hline Male & 87 & 79 & $90.8 \%$ & \multirow[t]{2}{*}{0.93} \\
\hline Female & 59 & 53 & $89.8 \%$ & \\
\hline \multicolumn{5}{|l|}{ Use of mobile cover } \\
\hline Covered phones & 108 & 102 & $94.4 \%$ & \multirow[t]{2}{*}{$0.048 *$} \\
\hline Uncovered phones & 38 & 30 & $78.9 \%$ & \\
\hline \multicolumn{5}{|c|}{ Site of mobile placement } \\
\hline Clothing (pocket) & 119 & 110 & $92.4 \%$ & \multirow[t]{2}{*}{0.62} \\
\hline Bag & 27 & 22 & $81.5 \%$ & \\
\hline \multicolumn{5}{|c|}{ History of mobile phone disinfection } \\
\hline Absent & 128 & 124 & $96.9 \%$ & \multirow[t]{2}{*}{$0.025^{*}$} \\
\hline Present & 18 & 8 & $44.4 \%$ & \\
\hline
\end{tabular}

*Statistically significant

Table.6 Resistance patterns of isolated bacteria from mobile phones

\begin{tabular}{|l|c|c|c|}
\hline Antibiotic & $\begin{array}{c}\text { Resistance of Gram- } \\
\text { positive bacteria } \\
\text { No= 147 }\end{array}$ & $\begin{array}{c}\text { Resistance of Gram- } \\
\text { negative bacteria } \\
\text { No= 55 }\end{array}$ & $\begin{array}{c}\text { Total resistance } \\
\text { No= 202 }\end{array}$ \\
\hline Ampicillin & $111(75.5)$ & $54(98.2)$ & $165(81.7)$ \\
\hline $\begin{array}{l}\text { Amoxicillin/ } \\
\text { clavulanic acid }\end{array}$ & $48(32.7)$ & $21(38.2)$ & $69(34.2)$ \\
\hline Cefotaxime & $61(41.5)$ & $40(72.7)$ & $101(50.0)$ \\
\hline Ceftazidime & $61(41.5)$ & $40(72.7)$ & $101(50.0)$ \\
\hline Ciprofloxacin & $59(40.1)$ & $18(32.7)$ & $69(34.2)$ \\
\hline Gentamicin & $50(34.0)$ & $19(34.5)$ & $35(17.3)$ \\
\hline Amikacin & $26(17.7)$ & $9(16.4)$ & $24(11.9)$ \\
\hline Imipenem & $17(11.6)$ & $7(12.7)$ & $121(59.9)$ \\
\hline Cotrimoxazole & $76(51.7)$ & $45(81.8)$ & - \\
\hline Vancomycin & $0(0.0)$ & NT & \\
\hline Valos & & & \\
\hline
\end{tabular}

Values are expressed as No (\%), NT: not tested Isolates of Bacillus anthracoid were not tested 
Table.7 Extended spectrum $\beta$-lactamases production by isolated Gram-negative bacteria

\begin{tabular}{|l|c|c|}
\hline $\begin{array}{l}\text { Gram-negative bacterial } \\
\text { isolates }\end{array}$ & Total number & $\begin{array}{c}\text { ESBL producers } \\
\text { No(\%) }\end{array}$ \\
\hline Escherichia coli & 21 & $9(42.9)$ \\
\hline Klebsiella pneumoniae & 17 & $5(29.4)$ \\
\hline Pseudomonas aeruginosa & 11 & $3(27.3)$ \\
\hline Acinetobacter baumannii & 6 & $1(16.7)$ \\
\hline Total & 55 & $18(32.7)$ \\
\hline
\end{tabular}

ESBL: Extended spectrum $\beta$-lactamases

Figure 1: Results of bacterial culture of samples collected from mobile phones.

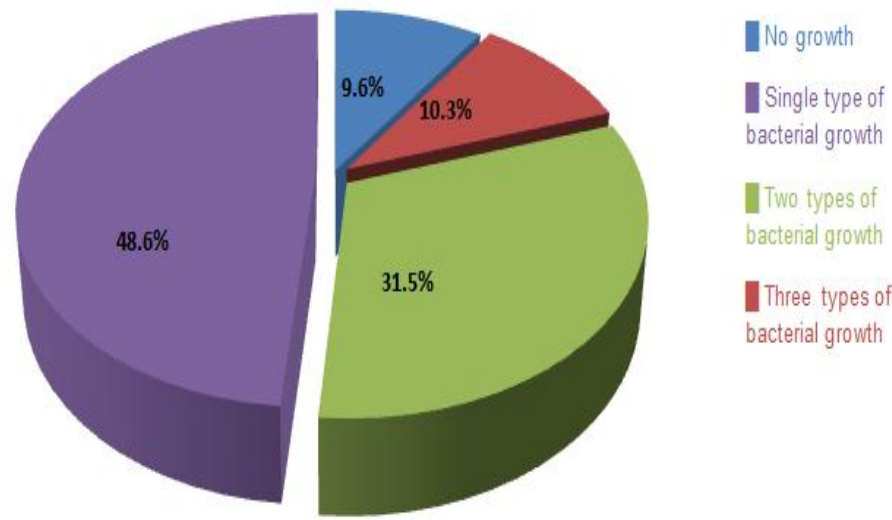

In our study, we investigated the possible risk factors for mobile phones contamination (Table 5). Both male and female HCWs had nearly the same rate of contamination of mobile phones. Covered mobile phones had a significantly higher contamination rate than the uncovered phones $(\mathrm{P}=0.048)$. Out of 146 HCWs participated in our study, $119(81.5 \%)$ used to place their mobile phones in the pockets of their attires. Mobile phones that were placed in the pockets had a higher contamination rate $(92.4 \%)$ than those kept in bags $(81.5 \%)$. However, the difference in contamination rate between both groups was not significant.

In the present study, $12.3 \%$ of participating HCWs (18/146) mentioned that they frequently disinfected their mobile phones with alcohol wipes. Mobile phones that belonged to this group of HCWs had a significantly lower rate of contamination (44.4\%) with $\mathrm{P}$ value of 0.025 . The remaining 128 HCWs $(87.7 \%)$ declared that they never disinfected their mobile phones as they were not aware of the associated risk for contamination. The type of mobile phone, whether touch-screen or keypad, was not assessed as a risk factor for contamination as all of the participating HCWs in this study used touch-screen phones.

The highest resistance of isolated organisms was demonstrated against ampicillin (81.7\%) followed by cotrimoxazole (59.9\%), cefotaxime $(50.0 \%)$, ceftazidime $(50.0 \%)$, ciprofloxacin $(38.1 \%)$, amoxicillin/ clavulanic acid (34.2\%), gentamicin (34.2\%), amikacin 
$(17.3 \%)$ and imipenem (11.9\%). All tested Gram-positive isolates were sensitive to vancomycin. Multidrug resistance was found in $41.1 \%$ of the tested isolates (83/202). Resistance patterns of Gram-positive and Gram-negative bacterial isolates were demonstrated in Table 6.

In the present study, ESBL production was identified in 18 out of $55(32.7 \%)$ isolated Gram-negative bacteria. Escherichia coli presented the highest ESBL production as $42.9 \%$ of the recovered isolates were ESBL producers, followed by $K$. pneumoniae (29.4\%), P. aeruginosa (27.3\%) and $A$. baumannii $(16.7 \%)$ as shown in Table 7.

Mobile phones, unlike fixed ones, are frequently used at patients care areas, thus, they can serve as a vehicle for transmission of HAIs into susceptible patients. Moreover, mobile phones are often used by HCWs outside and inside the hospital, and therefore, they can transfer external microbes into the healthcare setting environment (Jeske et al., 2007; Elkholy and Ewess, 2010).

During the present study, 146 mobile phones owned by HCWs of various professions and locations were sampled. Of the screened mobile phones, 132 (90.4\%) were contaminated with different numbers of bacteria. In concordance with our results, Badr et al., (2012) and Ulger et al., (2009)reported that $93.7 \%$ and $94.5 \%$ of mobile phones were contaminated respectively. The rate of contamination of mobile phones in our study was higher than those reported by Trivedi et al., (2011) (46.6\%) and Panchal et al., (2012) (65\%). However, Daka et al., (2015) and Tagoe et al., (2011) reported that $97.4 \%$ and $100 \%$ of mobile phones were contaminated respectively. Reported differences in the rate of mobile phones contamination could be attributed to the variations among $\mathrm{HCWs}$ including the degree of awareness towards the contamination risk posed by mobile phones, routine disinfection of phones, implementation of hand hygiene policy and frequency of handling mobile phones when providing medical care to the patients.

Out of the screened mobile phones, $48.6 \%$ showed single bacterial growth, $31.5 \%$ grew two types of bacteria and $10.3 \%$ grew three types of bacteria. Similar pattern of microbial contamination was previously reported (Pal et al., 2015; Daka et al., 2015). On the other hand, Rekha and Borkotoki reported that all positive cultures of mobile phones showed single microbial growth (Rekha and Borkotoki, 2017). Gram-positive bacteria constituted the majority of total isolates recovered from mobile phones which was consistent with previous studies (Al-Abdalall, 2010; Roy et al., 2013; Pal et al., 2015; Daka et al., 2015). The commonest recovered isolate was $S$. epidermidis that presented $41.3 \%$ of total isolates. Similar findings were reported in Egypt (Al-Mudares et al., 2012), India (Pal et al., 2015), Ethiopia (Daka et al., 2015) and Brazil (França et al., 2018). The predominance of $S$. epidermidis in the current study indicated that normal skin commensals could simply transfer to objects that might come in direct contact with the skin of HCWs. Even more, it is possibly that frequent and repetitive direct contact between the skin and mobile phones favors the transfer of these bacteria to the mobile phones (Goel and Goel, 2009). Although S. epidermidis is ordinarily non-pathogenic, it may cause HAIs in immunologically susceptible patients (Rekha and Borkotoki, 2017).

Staphylococcus aureus, a well-known nosocomial pathogen, was the second most commonly isolated organism in the present study. Methicillin resistance was detected among $27.9 \%$ of the recovered $S$. aureus isolates. Our findings were higher than those reported by Roy et al., (2013) (13.63\%), Tambe and Pai (2012) (16.9\%) and Pal et al., 
(2015) (21.05\%). However, other studies reported higher incidence of MRSA reaching up to $52 \%$ (Trivedi et al., 2011) and $83 \%$ (Tambekar et al., 2008) of total S. aureus isolates. In agreement with our results, Tambekar and his colleagues isolated $K$. pneumoniae and $P$. aeruginosa from mobile phones of HCWs (Tambekar et al., 2008).

In the current study, mobile phones owned by doctors were the least contaminated which could be explained by their higher awareness, medical knowledge and better implementation of hand hygiene. In agreement with our results, other reports showed that mobile phones owned by doctors had the lowest contamination rate followed by other professions (Tambe and Pai, 2012; Pal et al., 2015;Rekha and Borkotoki, 2017). The mobile phones screened in the outpatient clinics had the highest contamination rate (98.0\%) which could be attributed to the demanding busy working environment in the outpatient clinics and deficient time available for hand hygiene and disinfection of mobile phones.

Covered mobile phones were more contaminated than uncovered phones with a statistically significant difference $(\mathrm{P}=0.048)$. This could be explained by gaps and cracks present between the mobile phones and their covers that work as niches for contaminating bacteria. In addition, cleaning and disinfection of covered mobile phones might be more challenging and less effective because of these gaps. Out of $146 \mathrm{HCWs}$ participated in the present study, $87.7 \%$ were unaware of the role played by phones as a potential source of bacteria inside the healthcare settings, and therefore, they never decontaminated their mobile phones. In line with our results, Daka and his colleagues reported that $94.7 \%$ of the participating HCWs never cleaned their mobile phones (Daka et al., 2015).
In the present study, all tested Gram-positive isolates were sensitive to vancomycin. Besides, isolated bacteria demonstrated the least resistance to imipenem (11.9\%) and amikacin (17.3\%). Contrary to our findings, Akinyemi and his collaegues reported that fluoroquinolones were the most effective against the recovered isolates from mobile phones (Akinyemi et al., 2009).Variable antibiotic sensitivity patterns were reported in other studies (Trivedi et al., 2011; Pal et al., 2015). These variations may be explained by different geographical regions, the prevalence of resistant strains in healthcare and community settings, implementation of antibiotic policy and execution of infection control measures to limit the spread of resistance genes. Recovered E. coli isolates demonstrated the maximum ESBL production followed by $K$. pneumoniae. In agreement with our findings, Tekerekoglu and his colleagues reported that ESBL producing $E$. coli and $K$. pneumoniae were recovered from HCWs mobile phones (Tekerekoglu et al., 2011).

We demonstrated that mobile phones used by HCWs represent a potential threat, since $90.4 \%$ of screened mobile phones revealed bacterial contamination and $55.8 \%$ of the isolated bacteria were established nosocomial pathogens. Besides, S. epidermidis, which is a potential nosocomial pathogen, constituted $41.3 \%$ of total isolates. These findings highlighted the potential role of mobile phones in transmitting HAIs. Thus, HCWs should be aware that their personal mobile phones could both harbor and disseminate harmful bacteria inside and outside the healthcare setting environment.

The results of this study and similar reports could be used to educate HCWs about the possible health hazards carried by mobile phones to their patients as well as family members at home. Furthermore, these data 
could be used to provide the knowledge required to establish efficient prevention strategies. Such strategies might include limitation of mobile phones in ICUs and other high-risk areas, routine disinfection of mobile phones by alcoholic wipes or other disinfectants and routine performance of hand hygiene in particularly after handling the mobile phones and before touching the patient.

In conclusion, our study revealed that $90.4 \%$ of the cellular phones handled by HCWs were bacterially contaminated and thus may serve as a vehicle for transmission of HAIs. Isolated bacteria included both established and potential nosocomial pathogens. Methicillin resistant S. aureus constituted $27.9 \%$ of the total S. aureus isolates while $32.7 \%$ of the isolated Gram-negative bacteria were ESBL producers. Besides, MDR isolates constituted $41.1 \%$ of the tested bacteria. Most of the participating $\mathrm{HCWs}$, however, were unaware of the mobile phones-associated contamination risk. In order to reduce the role of mobile phones in transmitting HAIs, HCWs should be educated about the potential threat played by mobile phones along with limitation of their usage especially in high risk areas. Moreover, good practice including frequent disinfection of hands and mobile phones should be emphasized. Furthermore, study of effective and suitable disinfection methods for mobile phones should be considered.

\section{References}

Akinyemi, K., Atapu A., Adetona O., Coker A. 2009. The potential role of mobile phones in spread of bacterial infections. $\mathrm{J}$ infect DevCtries. 3(8): 628-32.

Al-Abdalall A., 2010. Isolation and identification of microbes associated with mobile phones in Dammam in eastern Saudi Arabia. J Family Community Med. 17(1): 11-14.

Al-Mudares, F., Al-Darzi W., Mansour M. 2012.
Mobile phone contamination by microorganisms in health facilities: comparing health care workers and patient visitors in a post-operative pediatric ICU. Student Pulse. 4(08): 1.

Arora, U., Devi P., Chadha A., Malhotra S. 2009. Cellphones A modern stay house for bacterial pathogens. JK Science. 11 (3): 127-29.

Badr, R., Badr H., Ali N. 2012Mobile phones and nosocomial infections. Int $\mathbf{J}$ Infect Control. $8(2)$.

Bellamy, K., Laban K., Barrett K., Talbot D. 1998. Detection of viruses and body fluids which may contains viruses in the domestic environment. Epidemiol Infect. 121(3): 673680.

Bhat, S., Hegde S., Salian S. 2011. Potential of Mobile Phones to Serve as a Reservoir in Spread of Nosocomial Pathogens. Online J Health Allied Sci. 10(2): 14-16.

Clinical and Laboratory Standards Institute. 2018. Performance Standards for Antimicrobial Susceptibility Testing.28th ed. CLSI supplement M100. Wayne, PA: Clinical and Laboratory Standards Institute.

Daka, D., Yihdego D., Tadesse E.2015.Level of Contamination and Antibiotic Resistance of Bacterial Isolates from Mobile Phone of HCW's in Hawassa Referral Hospital. Asian Journal of Medical Sciences. 7(3): 30-35.

Elkholy, M., Ewess I. 2010. Mobile (cellular) phones contamination with nosocomial pathogens in Intensive Care Units. Med J Cairo Univ.78(2): 1-5.

França, K., Pereira J., de Carvalho C., Medeiros R., Diniz A., Alves F. 2018. Bacterial Contamination of the Mobile Phones of Health Professionals in a Hospital Unit in the State of Paraíba, Brazil. Int J CurrMicrobiol App Sci. 7(07): 2598-2606.

Goel, M., Goel A. 2009. Beware your phone is -buggedll mobile phones of dental professionals a potential source of bacterial contamination - A bacteriological study. Indian Journal of Dental Science. 1(1): 4247.

Isaacs, D., Daley A., Dalton D., Hardiman R., Nallusamy R.1998. Swabbing computers in search of nosocomial bacteria. Ped Infect Dis. J. 17(6): 533. 
Jeske, H., Tiefanthaler W., Hohlrieder M., Hinterberger H., Benzer A. 2007. Bacterial contamination of anaesthetists hands by personal mobile phone and fixed phones use in the operating theatre Anaesthesia. 62(9): 904-6.

Kakote, S., More S., Gujar V., Mundhe S., Zahiruddin Q. 2012. Microbiological flora of mobile phones of resident doctors. J Bio Med Sci Eng. 5:98-8.

Pal, K., Chatterjee M., Sen P., Adhya S. 2015. Cell Phones of Health Care Professionals: A Silent Source of Bacteria. National Journal of Laboratory Medicine. 4(4): 33-38.

Panchal, C., Kamothi M., Mehta S. 2012. Bacteriological profile of cell phones of healthcare workers at tertiary care hospital. Journal of Evolution of Medical and Dental Sciences. 1(3): 198-202.

Rekha, Borkotoki U., 2017. Mobiles phones used by the health care personnel as a potential source of infections. Indian Journal of Applied Research. 7(4); 7(4): 71-73.

Roy, R., Kataria V., Dhand M., Mahawal B., Samwal P. 2013. A surveillance study of bacterial flora associated with mobile phones in a tertiary care hospital. International Journal of Biomedical and Advance Research. 4 (01): 56-58.

Schultz, M., Gill J., Zubaini S., Huber R., Gordin F. 2003. Bacterial contamination of computer keyboards in a teaching hospital. Infection Control Hospital Epidemiol. 24(4): 302-3.

Seliem, W., Sultan A.M. 2018.Etiology of early onset neonatal sepsis in neonatal intensive care unit - Mansoura, Egypt.J Neonatal Perinatal Med. 11(3): 323-330.

Singh, S., Acharaya S., Bhat M., Rao S., Pentapati K. 2010. Mobile phone hygiene: potential risks posed by use in the clinics of an Indian dental school. J Dent Educ. 74(10): 1153-8.

Tagoe, D., Gyande V., Ansah E. 2011. Bacterial contamination of mobile phones: when your mobile phone could transmit more than just a call. Webmed Central, Microbiology. 2(10): WMC002294. http://www. webmedcentral.com/article_view/2294[acce ssed 10 December 2018]

Tambekar, D., Gulhane, P.,Dahikar, S., Dudhane, M. 2008. Nosocomial Hazards of Doctor's mobile phones in hospitals. Journal of Medicine Science. 8(1): 73-76.

Tambe, N., Pai, C., 2012. A Study of microbial flora and MRSA harboured by mobile phones of health care personnel. International Journal of Recent Trends in Science and Technology.4(1): 14-18.

Tekerekoglu, M., Duman Y., Serindag A., Cuglan S., Kaysadu H., Tunc E., Yakupogullari Y. 2011. Do mobile phones of patients, companions and visitors carry multidrugresistant hospital pathogens? American journal of infection control. 39 (5): 383-385.

Trivedi, H., Desai K., Trivedi L., Malek S., Javdekar T. 2011. Role of mobile phone in spreading hospital acquired infection. A study in different group of health care workers. Natl J Integr Res Med. 2(3): 61-6.

Ulger, F., Essen S., Dilek A., Yanik K., Gunaydin M., Leblebicioglu H. 2009. Are we aware how contaminated our mobile phones are with nosocomial pathogens? AnnClin Microbial Antimirob. 8: 7.

Vergnano, S., Menson E., Kennea N., Embleton N., Russell A., Watts T., Robinson M., Collinson A., Heath P. 2011. Neonatal infections in England: the Neon surveillance network. Arch Dis Child Fetal Neonatal Ed. 96: F9-F14.

\section{How to cite this article:}

Amira M. Sultan and Mohammad A. Ahmed. 2019. Mobile Phones used by Healthcare Workers: The Potential Role in Transmission of Healthcare Associated Infections. Int.J.Curr.Microbiol.App.Sci. 8(05): 512-522. doi: https://doi.org/10.20546/ijcmas.2019.805.061 